Discussion Papers

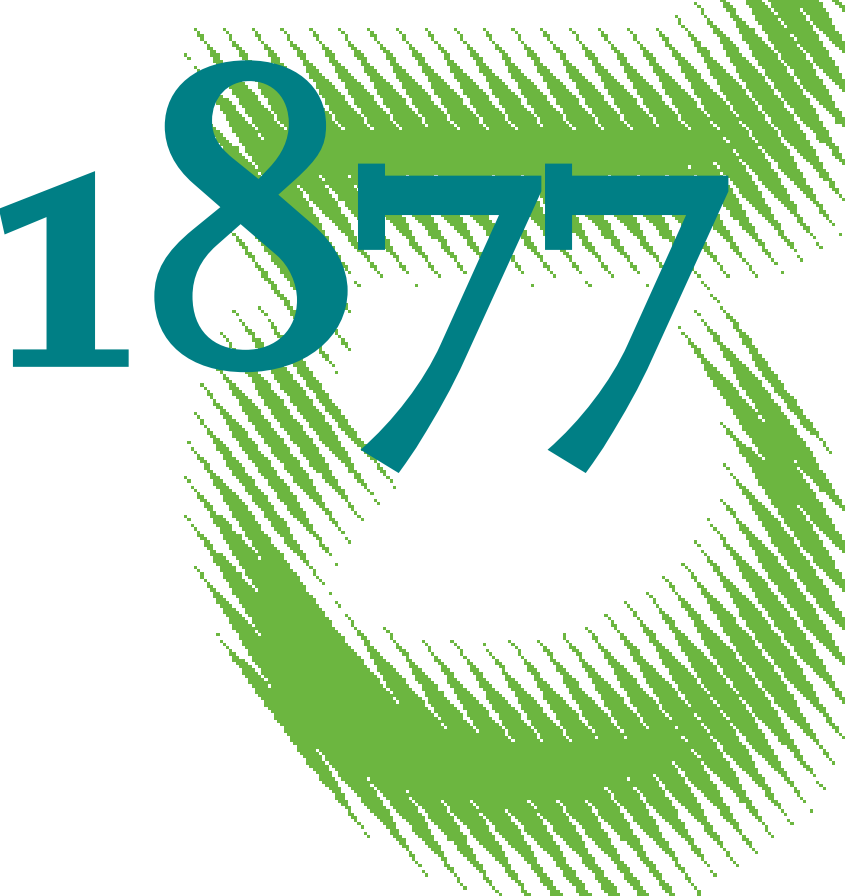

Make Sure the Kids Are OK: Indirect Effects of Ground-Level Ozone on Well-Being 
Opinions expressed in this paper are those of the author(s) and do not necessarily reflect views of the institute.

IMPRESSUM

(C) DIW Berlin, 2020

DIW Berlin

German Institute for Economic Research

Mohrenstr. 58

10117 Berlin

Tel. +49 (30) $89789-0$

Fax +49 (30) $89789-200$

http://www.diw.de

ISSN electronic edition 1619-4535

Papers can be downloaded free of charge from the DIW Berlin website:

http://www.diw.de/discussionpapers

Discussion Papers of DIW Berlin are indexed in RePEc and SSRN:

http://ideas.repec.org/s/diw/diwwpp.html

http://www.ssrn.com/link/DIW-Berlin-German-Inst-Econ-Res.html 


\title{
Make Sure the Kids are OK: Indirect Effects of Ground-Level Ozone on Well-Being
}

\author{
Julia Rechlitz $^{*} \quad$ Luis Sarmiento $^{\dagger} \quad$ Aleksandar Zaklan $^{\ddagger}$
}

June 9, 2020

\begin{abstract}
This paper uses a panel of German individuals and highly granular pollution data to test if air pollution affects adults' well-being indirectly through the health of their children. Results show that ozone decreases the well-being of individuals with children while not affecting persons without kids. We confirm the same effect for fine particulate matter and sulfur dioxide. Concerning the mechanism, we find that above-median earners drive this effect and that ozone causes losses in workdays to care for a sick child, providing evidence on the children's health channel to adults' welfare losses.
\end{abstract}

JEL codes: Q53, I31, I18, J22

Keywords: Air pollution, ozone, well-being, subjective health, children's health, parental investments

*Julia Rechlitz is a research associate at DIW Berlin and a doctoral candidate at the Berlin Institute of Technology. Postal address: DIW Berlin, Mohrenstr. 58, 10117 Berlin, Germany. E-Mail: jrechlitz@diw.de. Ph: +49-30-89789-467

${ }^{\dagger}$ Luis Sarmiento is a research associate at DIW Berlin and a doctoral candidate at the Berlin Institute of Technology. Postal address: DIW Berlin, Mohrenstr. 58, 10117 Berlin, Germany. E-Mail: asarmiento@diw.de. Ph: +49-30-89789-309. Corresponding author.

$\ddagger$ Aleksandar Zaklan is a senior researcher at DIW Berlin. Postal address: DIW Berlin, Mohrenstr. 58, 10117 Berlin, Germany. E-Mail: azaklan@diw.de. Ph: +49-30-89789-515. 


\section{Introduction}

Understanding the link between local air pollution, human health, and well-being is a relevant issue for economists. Air pollution causes economic costs through exacerbated morbidity (Kampa and Castanas, 2008), increases in mortality (Jayachandran, 2009; Knittel et al., 2016), expenditures on health services (Moretti and Neidell, 2011; Barwick et al., 2018), disruptions to human capital formation through school absenteeism (Currie et al., 2009; Chen et al., 2018), shocks to labor supply (Hanna and Oliva, 2015, Aragon et al., 2016), adverse effects on labor productivity (Zivin and Neidell, 2012, Chang et al., 2019), and reductions in self-reported measures of well-being (Luechinger, 2009; Levinson, 2012).

This paper considers the effect of air pollution on subjective well-being for the case of ground-level ozone $]^{1}$ Surprisingly, even though ozone is the second-most deadly air pollutant in Europe after particulate matter (Wolff, 2014), to the best of our knowledge, there is no evidence of its effect on self-reported well-being measures. One possible reason for this counter-intuitive lack of evidence is that ozone concentrations may not be high enough to affect the life satisfaction of the average person, although relevant for specific population groups more susceptible to the negative consequences of exposure.

In this study, we propose that ozone levels can affect adults' well-being directly through their health, and indirectly through the effect of exposure on family members. If the indirect mechanism is present, we expect stronger effects for persons with sensitive family members in their household. We disentangle the direct and indirect channels by investigating heterogeneous effects between individuals with and without children. $2^{2}$ The indirect channel is particularly relevant in places where ozone levels are not sufficiently high to affect adults' health but powerful enough to impact the health of more susceptible household cohabitants. Understanding whether such an indirect effect exists contributes to a fuller understanding of air pollution's welfare consequences.

To our knowledge, this paper is the first to examine the indirect effect of family environments on the relationship between pollution and well-being and the first to find a consistent

\footnotetext{
${ }^{1}$ In contrast to ground-level ozone, which is mostly human-made and harmful to flora and fauna, the bulk of ozone in the earth's atmosphere occurs naturally in the stratosphere, between about $10 \mathrm{~km}$ and $50 \mathrm{~km}$ above the earth's surface. This ozone layer is vital for protecting life from the sun's ultraviolet radiation. In the remainder of the paper, we write ozone instead of ground-level ozone for brevity.

${ }^{2}$ By "individuals with children" we mean people sharing their households with children. By "individuals without children," we mean both persons without children and those with children who no longer share the same family house. Our data do not allow us to distinguish between the latter two cases.
} 
negative impact of ozone exposure. We further contribute by focusing on the mechanisms behind the well-being result, i.e., the health of family members and the role of heterogeneous family environments, proxied by income.

Focusing on the well-being effects of ozone is advantageous for three reasons: First, substantial epidemiological evidence shows that ozone exposure decreases objective health outcomes for both adults and children, with children being especially affected $!^{3}$ Second, ozone is particularly relevant because while the concentrations of other pollutants decreased in recent years due to policy interventions, average ozone levels have remained stable. Furthermore, current levels of ozone are likely to increase because of climate change triggered heatwaves (Rosenzweig et al., 2004; Selin et al., 2009). Third, the correlation of ozone with other contaminates is often negative, allowing us to provide lower-bound estimates and alleviate spurious correlation concerns.

We analyze the effects of ozone on two measures of subjective well-being: satisfaction with one's health, and satisfaction with one's life. Health satisfaction targets the health channel of air pollution, while the broader measure of life satisfaction encompasses further factors affecting an individual's well-being, such as indirect welfare effects stemming from the impact of ozone on the environment, the family, and the community. Evaluating subjective welfare outcomes is informative, especially in contexts of moderate ozone concentrations and healthy populations. If ozone affects the health of individuals, they may increase their demand for health services, decrease labor supply, or suffer productivity losses, which leads to additional economic costs. Conversely, if ozone only moderately deteriorates objective health outcomes, it may not lead to immediate economic costs when the individual generally feels well ${ }_{4}^{4}$ Furthermore, life satisfaction measures are also attractive from an identification perspective as they respond to short and medium-term shocks, like the variation of air pollution. Existing literature has already successfully exploited this sensitivity of life satisfaction to short-term events (e.g. Luechinger, 2009; Levinson, 2012).

We identify the effect of ozone on individuals from short and medium-term variations in ozone levels. Specifically, we combine geo-coded data on daily ozone levels from measuring stations across Germany with geo-coded individual-level data on subjective health and life

\footnotetext{
${ }^{3}$ Additional direct losses in well-being may occur through aesthetic effects, such as foggy air due to pollution (Levinson, 2012).

${ }^{4}$ Validating the results for the subjective variables (well-being and health) using objective data is beyond this paper's scope due to data availability. Especially in Germany, data on children's health are not readily available. However, we refer the reader to the extensive body of literature linking air pollution and objective outcomes.
} 
satisfaction between 2005 and 2015 from the German Socio-Economic Panel Study (SOEP), a representative survey of German individuals. We exploit information on the precise date of the SOEP interview to assign weekly, monthly, and quarterly exposure levels to each individual through inverse distance weighting. Our preferred specification estimates the effects of ozone on the health and life satisfaction of adults with and without children through a set of multipollutant regressions. In these regressions, we control for time and individual fixed effects, individual-level covariates, county-level macro variables, weather-related data, and additional relevant pollutants: carbon monoxide $(\mathrm{CO})$, fine particulate matter $\left(\mathrm{PM}_{25}\right)$, nitrous dioxide $\left(\mathrm{NO}_{2}\right)$, and sulfur dioxide $\left(\mathrm{SO}_{2}\right)$.

The study also explores the channels through which households with children experience losses in life satisfaction by analyzing the impact of ozone exposure on a proxy for kids' health, the number of days lost because a child is sick. Moreover, we explore heterogeneous effects between high and low-income households and examine the sensitivity of our results through several robustness tests. First, we check whether the results for adults with children also hold for $\mathrm{PM}_{25}$ and $\mathrm{SO}_{2}$. Second, randomizing our pollution exposure variables across individuals and across time allows us to check for spurious causality. Third, we are mindful of the need to ascertain that estimations are robust to the cardinalization of the ordinal well-being outcomes (e.g. Bond and Lang, 2018). As such, we re-formulate the 11-point outcome scales for life and health satisfaction as binary variables and re-estimate our main specification using a fixedeffects Probit model to check whether our results depend on the ordinal nature of the well-being outcomes.

Results show statistically and economically significant adverse effects of ozone on the life satisfaction of adults sharing their households with children. In contrast, such effects are absent for persons living in children-less households. The economic significance in families with children increases with the level of temporal aggregation: point estimates grow in absolute value between weekly, monthly, and quarterly time-windows. This result is in line with the epidemiological literature, which shows that the effects of ozone on health become more pronounced with prolonged exposure, suggesting that - under the assumption that the sensitivity of individuals' life satisfaction to ozone is not affected by childbirth - ozone pollution diminishes the welfare of adults with children while not significantly affecting childless persons. In contrast to our results on life satisfaction, we do not find any effect of ozone on health satisfaction, neither for persons without children nor for individuals sharing their households with children. 
Our findings suggest that ozone concentrations in Germany are not high enough to affect the subjective health of adults in general, but are suggestive regarding the negative consequences of ozone on the health of children, and their indirect effect on the life satisfaction of the adult population. Furthermore, robustness tests confirm that the main result is not limited to ozone. We also find similar effects for $\mathrm{PM}_{25}$ and $\mathrm{SO}_{2}$.

Exploring the mechanism behind the well-being effect, we find that adults lose time at work to care for their sick child due to ozone, providing direct evidence that the health of children is one of the elements driving the well-being effect, either through empathy, worries about missing work, or costs of providing care. Moreover, above-median earners drive the well-being effect. This result is in line with the literature on parental investments, which shows that family environments exert strong and long-lasting impacts on child outcomes (Heckman and Mosso, 2014; Francesconi and Heckman, 2016). In particular, high-income families invest more heavily in their offspring, (Carneiro and Ginja, 2016; Carneiro et al., 2013). The indirect influence of ozone - and other air pollutants - on persons with children should be taken into account in further research and policy debates regarding the costs and benefits of reducing air pollution.

In our view, the two contributions most relevant to ours are Luechinger (2009) and Levinson (2012). Luechinger (2009) analyzes the effect of $\mathrm{SO}_{2}$ on the subjective life satisfaction of SOEP households using a quasi-experimental design. His study finds a significant negative impact of $\mathrm{SO}_{2}$ pollution on individuals' life satisfaction. Levinson (2012) uses data from the General Social Survey (GSS), collected by the National Opinion Research Center and daily variation in air pollution to show that $\mathrm{PM}_{10}$ also diminishes life satisfaction of U.S. individuals. Our paper adds to the literature compared to Luechinger (2009) and Levinson (2012) in several respects: First, it studies the effects of a different pollutant, ozone. Second, it explores the channels through which pollution affects life satisfaction. Third, it leverages the higher quality of our data, mainly better coverage compared to Levinson (2012) and better regional granularity compared to Luechinger (2009), to pursue a more precise identification, and fourth, it explores how different time aggregations of pollution affect the coefficients of our causal variable.

Further studies on the link between air pollution and life satisfaction provide additional evidence on the relationship between these variables: Rehdanz and Maddison (2008) use SOEP data to find a negative association between people's claim to be affected by higher air pollution and their levels of life satisfaction. Ferreira and Moro (2010) use the same method at the level 
of Irish electoral districts and find similar results. Cunado and De Gracia (2013), Ferreira et al. (2013) and Ambrey et al. (2014) also find a negative association between life satisfaction and air pollution. Zhang et al. (2017) find that an air pollution index composed of $\mathrm{SO}_{2}, \mathrm{NO}_{2}$, and $\mathrm{PM}_{10}$ decreases subjective mental health and increases hedonic unhappiness. However, to our knowledge, this literature does not explicitly explore channels through which air pollution affects well-being.

\section{Background: Ozone and health}

There is a significant literature on the direct impacts of local air pollution on objective health outcomes. Effects include increased mortality (Jayachandran, 2009, Knittel et al., 2016), negative consequences on the respiratory and circulatory systems (Amster et al., 2014), higher hospitalization rates (Iskandar et al., 2012), greater medicine intake (Ostro et al., 2001), disruptions in human capital through exacerbated children morbidity (Chen et al., 2018), and higher expenditures on health services (Moretti and Neidell, 2011, Barwick et al., 2018).

Regarding ozone, evidence shows that exposure also increases the morbidity and mortality of affected persons (Schwela, 2000, Chay and Greenstone, 2003; Knittel et al., 2016). Short-term effects include decreases in lung capacity, inflammations of the respiratory tract, and a higher frequency of asthma attacks. At the same time, long-term exposure increases the risk of developing chronic lung disease (EPA, 2016), and potentially increase the probability of developing cancer (Rocks et al., 2017; Kim et al., 2018). The health effects of ozone are most potent among high-risk populations, like children, the elderly, outdoor workers, and individuals suffering from respiratory ailments. Gryparis et al. (2004) use data from 24 different European urban agglomerations to conclude that an increase of 10 milligrams per cubic meter $\left(\mathrm{mg} / \mathrm{m}^{3}\right)$ in the levels of 1-hour maximum daily ozone concentrations raise total mortality rates by $0.31 \%$. Regarding morbidity, Devlin et al. (1991) conclude that even at ambient levels as low as eight particles per billion ( $\mathrm{ppb}$ ), ozone exposure has negative impacts on the respiratory system. Koken et al. (2003) find that ozone correlates with hospitalizations of elderly adults due to cardiovascular ailments, while Friedman et al. (2001) uses variations in environmental policies during the Atlanta summer games to infer that the associated drops in peak daily ozone levels (81.3 to $58.6 \mathrm{ppb}$ ) lead to fewer asthma-related emergency room admissions. Moretti and Neidell (2011) use instrumental variable techniques to estimate the financial costs of ozone 
on hospital admissions. They determine that ozone exposure causes annual costs of US\$ $55 \mathrm{~m}$ from respiratory hospitalizations and avoidance behavior.

Studies focusing on the effect of ozone on children's health have also produced substantial evidence regarding the damaging impact of ozone on respiratory health, lung capacity, long-term inadequacy of lung growth, increases in hospitalizations, mortality, and use of asthma medicine (Bates, 1995). The literature shows that ozone affects children more strongly than adults. Lleras-Muney (2010) studies the effect of pollution on children's hospitalization rates by using the relocation of military personnel as a source of exogenous variation in exposure. She finds that an increase in ozone exposure by one standard deviation increases the hospitalization rates of military children between $8 \%$ and 23\%. Burnett et al. (2001) analyze the effects of ozone on the hospitalization rates of children under two years of age. They find that increasing the average concentration of ozone to one-hour maximum values typically found in summertime (45 ppb) would increase daily hospitalizations due to respiratory ailments by 35\%. Thurston et al. (1997) find significant correlations between lower lung capacity and high levels of atmospheric ozone when studying the effect of ozone in children between seven and thirteen years old. Ostro et al.(2001) find that asthmatic children between the ages of eight and thirteen increase medicine use during higher ozone episodes. Lee et al. (2002) observe that, for South Korean children under the age of fifteen, the risk of asthma-related hospitalization increases between $7 \%$ to $13 \%$ when atmospheric ozone rises by $21 \mathrm{ppb}$. Tolbert et al. (2000) find that increasing the 8-hour maximum ozone level by $20 \mathrm{ppb}$ increases pediatric emergency room visits due to asthma by $4 \%$. Finally, regarding the long term consequences of exposure to ozone on lung capacity, Galizia and Kinney (1999) conclude that exposure to high levels of ozone during childhood affects the lung capacity of university students several years after exposure to high ozone values.

Based on the epidemiological evidence and under the reasonable assumption that the utility of children enters the utility function of adults sharing the same household, we hypothesize that there are two channels for ozone to affect welfare outcomes of adult individuals: The first channel captures the direct effect of ozone through their health, which is the channel investigated in the existing literature. The second channel is through family effects: Adults' outcomes are affected by their children's welfare. We hypothesize that in the case of ozone, the second channel is worth examining because children are a sensitive group to the effects of atmospheric ozone. 


\section{Data}

\subsection{Data sources}

We obtain household and personal data from the German Socio-economic Panel Study (SOEP). The SOEP is a representative longitudinal panel study that started in West Germany in 1984. Between 2005 and 2015, SOEP surveyed 30,051 different households and 80,339 unique individuals. On average, individuals spend around five years as members of the panel.

Our primary outcome variables are responses to questions asking individuals to rate their life and health satisfaction. The questions are as follows: "How satisfied are you with your life, all things considered?" and "How satisfied are you with your health, all things considered?" Respondents provide answers on an eleven-point scale from zero (completely dissatisfied) to ten (completely satisfied) (Richter et al., 2013). SOEP also provides two critical pieces of information necessary for the causal identification of the effects of ground-level ozone on life and health satisfaction: First, it contains the geo-coordinates of surveyed households on a strictly confidential basis. We use these geo-codes and inverse distance weighting to match surveyed individuals to nearby pollution measuring stations, enabling a clean spatial matching of exposure and individuals. Second, the survey also contains information on the exact day of the interview, allowing for a precise temporal match of individuals and their ozone exposure. Additionally, the SOEP also has information on a broad set of sociodemographic and economic controls, such as marital status, age, gender, income, and employment.

Data on the daily concentration of ozone and other air pollutants come from the German Environmental Agency (Umweltbundesamt, henceforth UBA). UBA maintains an extensive network of monitoring stations measuring different types of contaminants. In total, UBA has 378 stations measuring the concentration of ozone in the environment.5 Figure 1 shows the spatial distribution of ozone monitoring stations across Germany. Stations concentrate in urban clusters such as Berlin in the northeast, Hamburg in the north, and the Ruhr area in the west.

Additionally, the German meteorological service (Deutscher Wetterdienst, DWD) provides weather data from its monitoring stations. We also match the weather data to the individuallevel data with inverse distance weighting. Finally, Eurostat provides county-level macroeconomic controls. The macroeconomic variables we use in this paper are the unemployment rate,

\footnotetext{
${ }^{5}$ Because of malfunction and routine maintenance, stations measuring ozone have missing values around $10 \%$ of the time.
} 


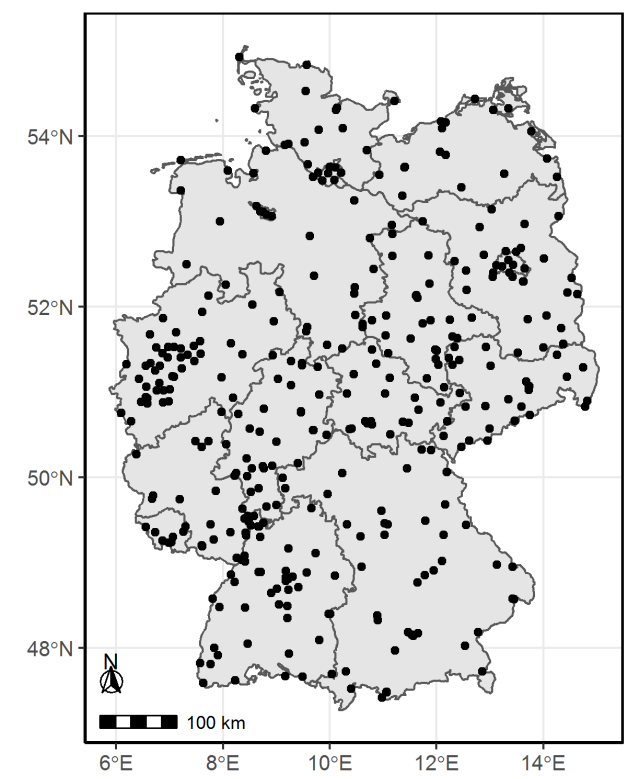

Source: German Environmental Agency.

gross domestic product per capita, and population density.

\subsection{Ground-level ozone in Germany}

Our primary explanatory variable is ground-level ozone. In Germany, over the period 20052016, ozone had an average annual concentration of 47.7 micrograms per cubic meter $\left(\mu \mathrm{g} / \mathrm{m}^{3}\right)$, with a standard deviation of $24.45 \mu \mathrm{g} / \mathrm{m}^{3}$ and a maximum of $199.9 \mu \mathrm{g} / \mathrm{m}^{3}$. Ozone levels are higher in German rural areas $\left(57.4 \mu \mathrm{g} / \mathrm{m}^{3}\right.$ on average for 2006-2015) than in suburban (45.4 $\left.\mu \mathrm{g} / \mathrm{m}^{3}\right)$ and urban $\left(42.1 \mu \mathrm{g} / \mathrm{m}^{3}\right)$ districts. Furthermore, even as in recent years the concentration of most criteria pollutants decreased, mostly because of the contemporary implementation of public policies such as clean action plans and low emission zones, the average concentration of ozone has remained stable 6

Yet, ozone still varies significantly within the year. Given that primary contaminants' interaction with solar radiation triggers the creation of ozone, its levels are higher during the summer months. Moreover, as the levels of primary pollutants and solar radiation vary across

\footnotetext{
${ }^{6}$ Both the higher level of ozone in rural areas and its steady long term concentration respond to the fact that ozone is a secondary environmental pollutant. On the one hand, solar radiation, together with precursor contaminants, forms ozone. On the other, nitric oxide (NO) also degrades ozone back into oxygen. The relationship between ozone and its precursors is non-linear. For example, in areas with high levels of NO, such as urban centers and traffic areas, ozone degrades at faster rates, leading to lower ozone levels than in rural areas with lower levels of ozone precursors. This phenomenon is referred to as the "ozone paradox."
} 
locations, the concentration of ozone also varies substantially across space. Figure 2 shows the spatial distribution of average ozone levels across German states during the four seasons of the year. We observe lower ozone levels in densely populated states such as North RhineWestphalia, Hamburg and Bremen, and higher levels in more rural areas, such as SchleswigHolstein and Saxony-Anhalt. Regional concentrations vary significantly by season. In the winter, the states with higher ozone levels are the more rural Eastern and Northern states, while in the summertime, due to the influence of solar radiation on ozone formation, also southern states such as Baden-Wuerttemberg and Hessen exhibit higher exposure levels.

Figure 2: Ozone concentrations in Germany by season.
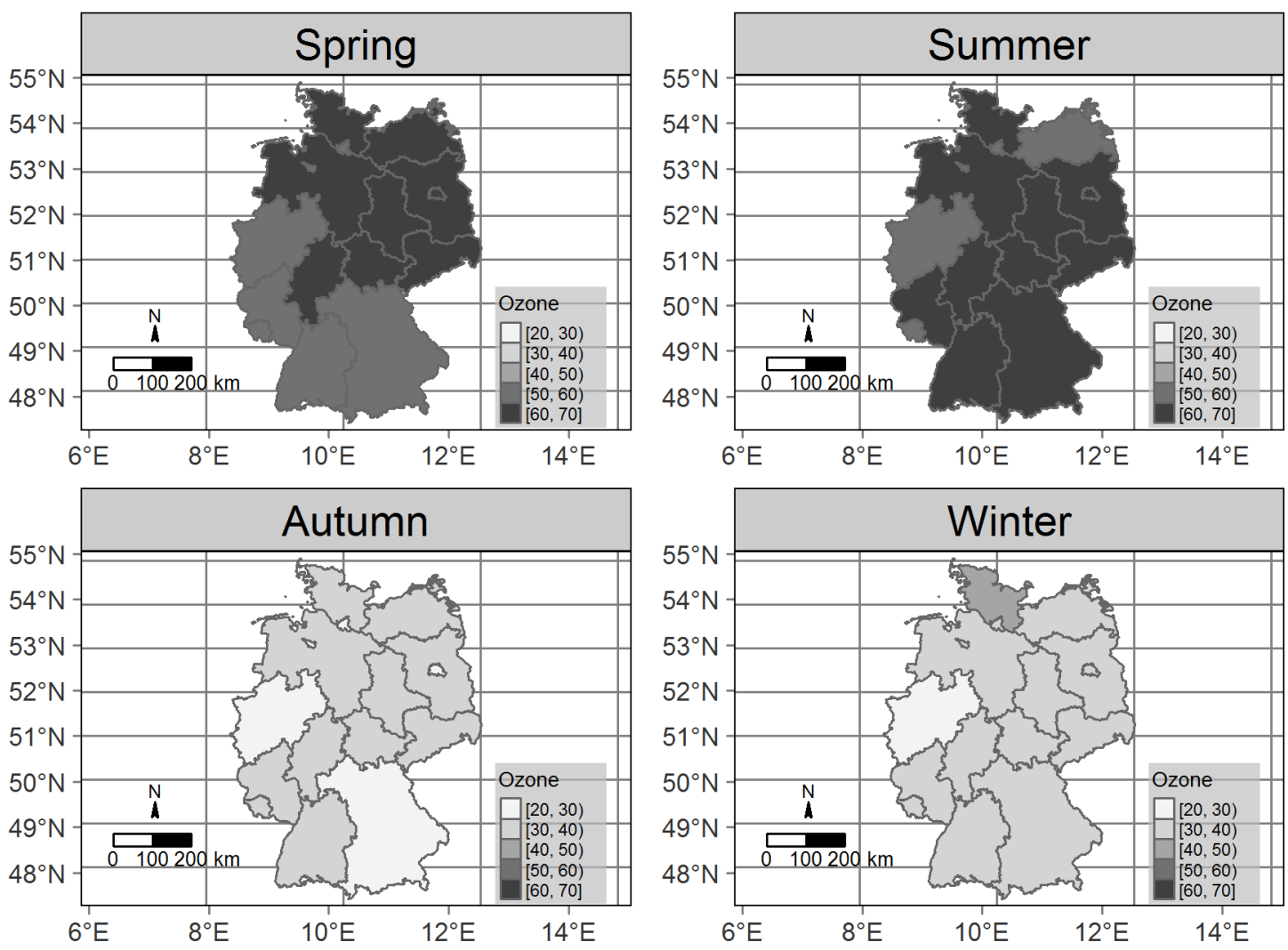

Source: German Environmental Agency.

We assign ozone exposure to individuals using inverse distance weighting (IDW) between ozone monitoring stations and individuals' dwellings. IDW is a spatial interpolation technique that approximates the value of a point in space by weighting the values of comparable neighbors.7 It assigns individual pollution measures to each person by providing more

\footnotetext{
${ }^{7}$ Formally, IDW interpolation takes the form:
} 
weight to stations located near the person's dwelling.

\subsection{Individual-level data}

Table 1 presents basic descriptive statistics for the subsample of SOEP individuals residing within ten kilometers of ozone measuring stations. The mean of both life and health satisfaction is in the upper part of their categorical distribution, with a mean value of 7.23 for life satisfaction and 6.73 for health satisfaction. On average, surveyed individuals have an income of 43 thousand Euro, are in their late $40 \mathrm{~s}$, and are unemployed $4 \%$ of the time. We observe differences between individuals by child status. People with children are younger, generate a higher income, and are unemployed somewhat more frequently than those in the childless group. We control for these differences in the regression analysis. In terms of pollution, individuals in our regression sample are exposed to levels of ozone well below the German average, as they predominantly reside in urban areas.

Table 1: Descriptive overview

\begin{tabular}{|c|c|c|c|c|c|c|}
\hline & \multicolumn{2}{|c|}{ Full sample } & \multicolumn{2}{|c|}{ With children } & \multicolumn{2}{|c|}{ Without children } \\
\hline & Mean & Std. Dev & Mean & Std. Dev. & Mean & Std. Dev. \\
\hline \multicolumn{7}{|l|}{ SOEP data: } \\
\hline Life satisfaction & 7.23 & 1.72 & 7.43 & 1.64 & 7.13 & 1.76 \\
\hline Health satisfaction & 6.73 & 2.20 & 7.19 & 2.03 & 6.50 & 2.25 \\
\hline Workdays lost to child sickness & 0.38 & 2.16 & 1.01 & 3.42 & 0.00 & 0.00 \\
\hline Age & 48.20 & 17.32 & 38.77 & 8.97 & 53.16 & 18.55 \\
\hline Income & 43.55 & 35.37 & 47.91 & 31.15 & 41.26 & 37.19 \\
\hline Employment & 0.04 & 0.20 & 0.06 & 0.24 & 0.03 & 0.18 \\
\hline \multicolumn{7}{|l|}{ Pollution data: } \\
\hline Ozone $\left(\mathrm{O}_{3}\right)$ & 14.34 & 12.30 & 14.70 & 12.33 & 14.15 & 12.27 \\
\hline Fine $\mathrm{PM}\left(\mathrm{PM}_{25}\right)$ & 6.42 & 5.82 & 5.44 & 4.92 & 6.93 & 6.18 \\
\hline Sulfur dioxide $\left(\mathrm{SO}_{2}\right)$ & 1.27 & 1.22 & 1.09 & 1.06 & 1.36 & 1.29 \\
\hline Carbon monoxide (CO) & 0.16 & 0.13 & 0.14 & 0.11 & 0.17 & 0.13 \\
\hline Nitrous dioxide $\left(\mathrm{NO}_{2}\right)$ & 6.51 & 5.69 & 6.04 & 5.13 & 6.75 & 5.95 \\
\hline Number of observations & \multicolumn{2}{|c|}{46,677} & \multicolumn{2}{|c|}{30,591} & \multicolumn{2}{|c|}{16,086} \\
\hline
\end{tabular}

Notes: Employment is a binary variables indicating if the person is employed in each year or not. Income is in thousand Euro. All pollutants are measured in $\mu \mathrm{m}^{3}$.

$$
V_{j t}=\left\{\begin{array}{c}
\frac{\sum_{i}^{N} \omega\left(\text { dist }_{i j}\right) * \text { pol }_{i t}}{\sum_{i}^{N} \omega\left(\text { dist }_{i j}\right)} \\
\text { pol }_{i t} \rightarrow \text { dist }_{i j}=0
\end{array}\right\} \Longrightarrow \omega\left(\text { dist }_{i j}\right)=\frac{1}{\operatorname{distance}\left(x_{i}, x_{j}\right)^{p}}
$$

where $V_{j t}$ is the weighted value of pollution at household $j$ at time $t, p_{i t}$ is the value of pollution at station $i$ at time $t, x_{i}$ and $x_{j}$ the geographical coordinates of station $i$ and households $j$, and $d_{i s t} t_{i j}$ is the distance between pollution station $i$ and household $j$. The power factor $p$ modifies the weighting load; the greater $p$, the greater the weight of closer stations. We use a weight of two, as recommended by De Mesnard (2013) for air pollution. To focus on local ozone concentration, we cut off stations located further away than 10 kilometers. Finally, we use the great circle distance formula for maximum precision in calculating the distance between coordinate points (Shumaker and Sinnott, 1984) . 
Figure 3 shows the distribution of answers for health and life satisfaction. For both variables, the highest frequency of responses is between seven and nine. On average, individuals were mostly satisfied with their life during the sample period. We observe that life and health satisfaction are correlated, although the correlation is not perfect. Scores for health satisfaction are spread across the scale more than for life satisfaction.

Figure 3: Life and health satisfaction of SOEP individuals
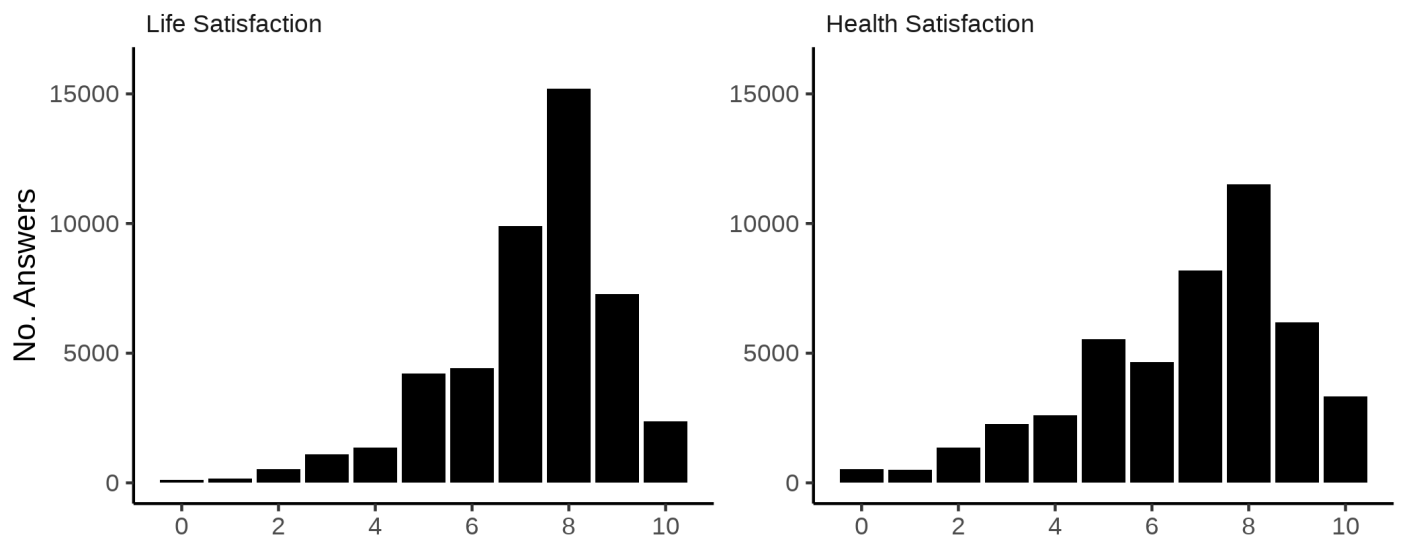

Source: SOEP

Figure 4 portrays the temporal evolution of life and health satisfaction. The graphs exhibit similarities and differences in the evolution of both variables over time. Both life and health satisfaction decrease during the years of the financial and economic crisis of 2008/2009, while in the ensuing years, they increase in line with the positive development of the German business cycle and the concurrent rise in employment.

\section{Research Design}

\subsection{Identification}

The research design identifies the effect of ozone on individuals from within-year variation in ozone levels, at weekly, monthly, and quarterly frequencies $\left.\right|^{8}$ Our identification strategy helps mitigate concerns about the endogeneity of pollution levels, and it is similar to the approach by Levinson (2012), except that the higher quality of our data allows us to exploit more variation

\footnotetext{
${ }^{8}$ Our data only allow us to map ozone levels to each person's dwelling. However, especially kindergartens and primary schools usually are close to peoples' homes. We thus consider our assumption that ozone levels at individuals' dwellings closely track especially those at schools and kindergartens to be fair.
} 
Figure 4: Life and health satisfaction of SOEP individuals over time
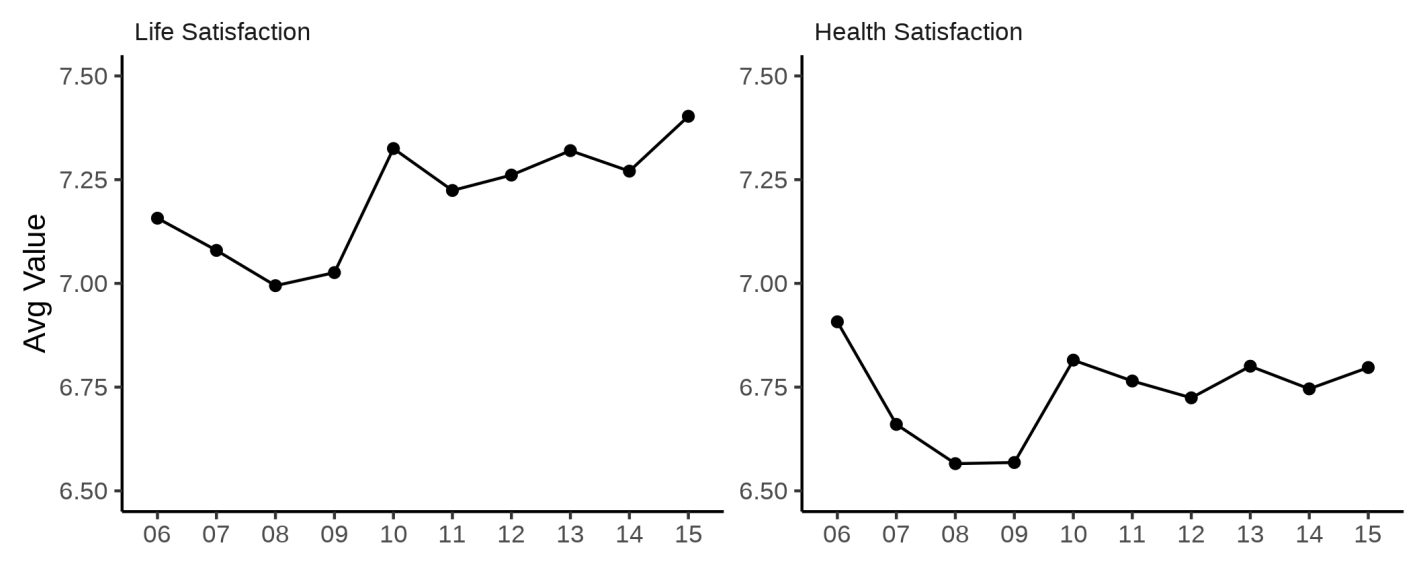

Source: SOEP

in ozone concentrations across space and time (Figure 2). The design controls for unobservable heterogeneity through individual, year, month, and day-of-the-week fixed effects. Additionally, we control for covariates at the individual and county levels, as well as for other pollutants and weather conditions that play a role in ozone generation.

SOEP interviews take place at different times of the year all over Germany. Roughly half of the surveys take place between September and March - months with low ozone concentrations - while the other half occurs during the period April and August when ozone levels are higher (Figure 5, left panel). Besides, the interview dates also vary at the individual level across the years. On average, SOEP interviews for each person occur with a standard deviation of 28 days (Figure 5, right panel). In addition to variation across the year, interviews also vary by weekday. Even if the questionnaire were filled on the same date in two consecutive years, ozone values would be likely to change because of differences in ozone concentrations depending on the day of the week (Figure 6, left panel). Together, these sources of temporal variation provide significant in-person variation in exposure.

One concern is that ozone levels may be highly correlated with other pollutants so that multicollinearity may hinder the identification of effects. Figure 6 shows that ozone variation differs strongly from $\mathrm{PM}_{25}$ and $\mathrm{SO}_{2}$ across the week, the year, and over our sample period. In addition to differences in variation over shorter intervals, ozone is the only air pollutant that has not seen a significant decrease throughout the study period. (Figure 6, right panel). Another potential concern is self-selection through moving behavior. Some individuals may move to areas with less pollution. To avoid this issue from contaminating our results, we exclude 
Figure 5: Distribution of SOEP interviews over days of the year

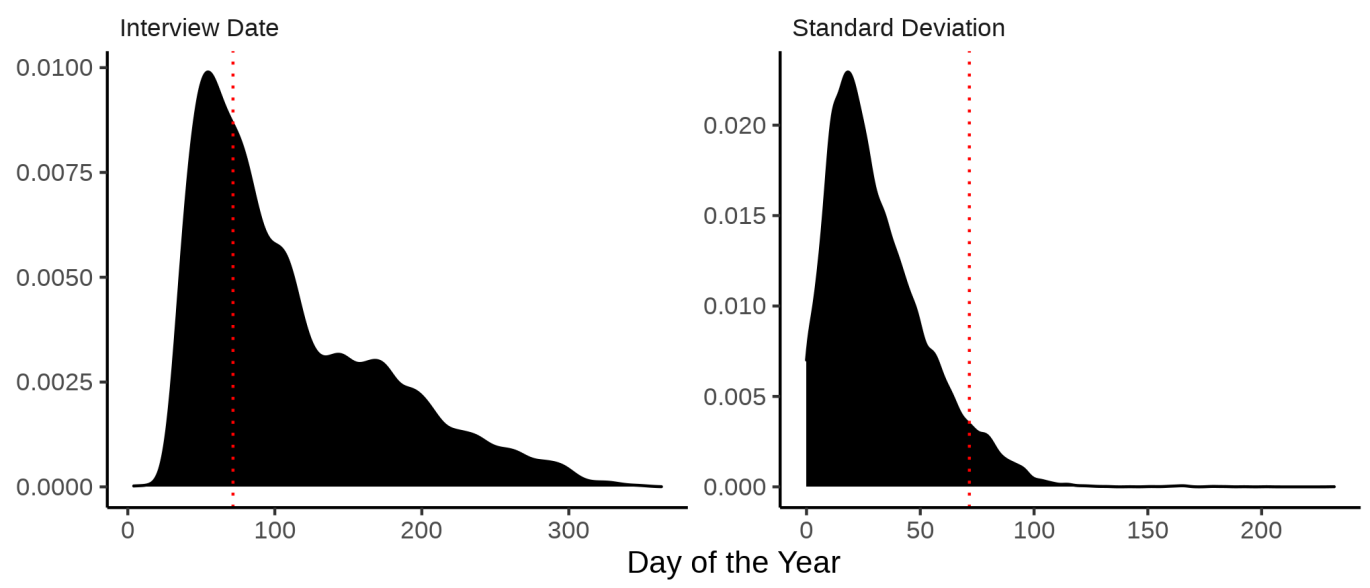

Source: SOEP

individuals that moved from dwellings during the sample period: By eliminating movers, we estimate a lower bound of the effect of ozone, as people that relocate due to ozone exposure are likely to more sensitive than those who remain in their prior location.

Figure 6: Temporal variation in ozone, fine particulate matter and sulfur dioxide
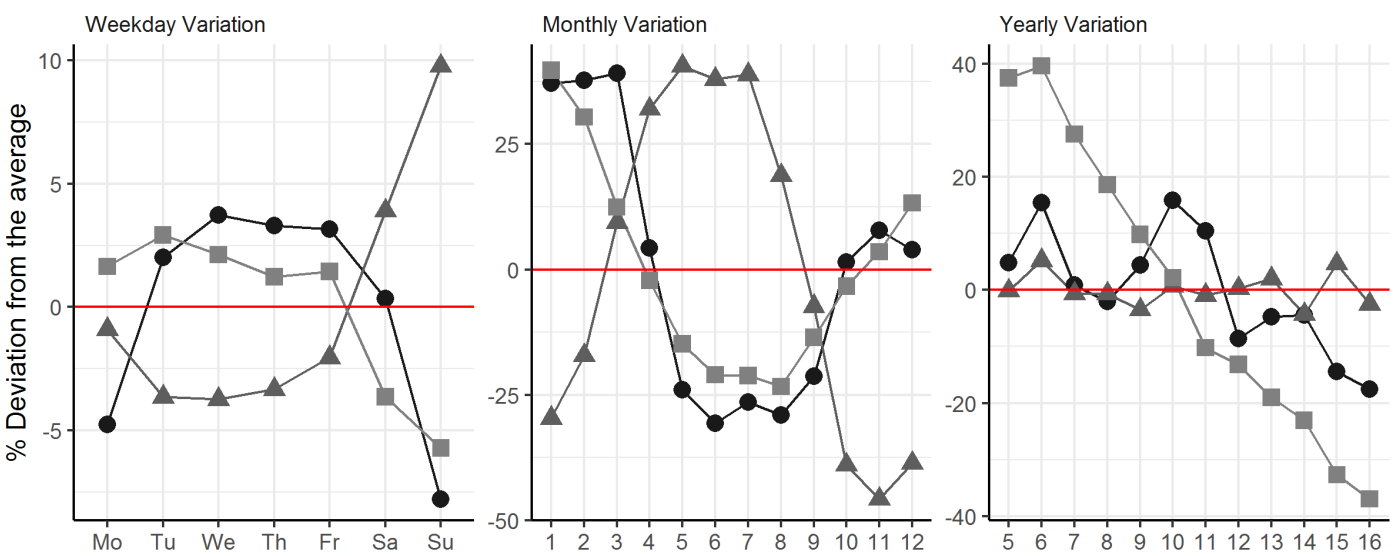

Fine Particle Matter - Ozone - - Sulfur Dioxide

Source: German Environmental Agency.

\subsection{Empirical model}

Our main analysis estimates the following equations: 


$$
\begin{aligned}
& L S_{i t}=\alpha+\rho \text { Ozone }_{i t}+\boldsymbol{X}_{\boldsymbol{i t}}^{\prime} \boldsymbol{\alpha}+\boldsymbol{Y}_{\boldsymbol{c t}}^{\prime} \boldsymbol{\beta}+\gamma_{t}+\lambda_{i}+\epsilon_{i t}, \\
& H S_{i t}=\alpha+\rho \text { Ozone }_{i t}+\boldsymbol{X}_{\boldsymbol{i t}}^{\prime} \boldsymbol{\alpha}+\boldsymbol{Y}_{\boldsymbol{c t}}^{\prime} \boldsymbol{\beta}+\gamma_{t}+\lambda_{i}+\epsilon_{i t},
\end{aligned}
$$

$L S_{i t}$ and $H S_{i t}$ are subjective life and health satisfaction values for each individual $i$ on the interview date $t$. Ozone $e_{i t}$ is the exposure of individual i to ozone. $\rho$ represents the coefficient of interest on pre-interview ozone exposure of different lengths. We estimate short-term effects by using the ozone exposure during the week prior to the interview as the main explanatory variable and capture longer-term effects by using rolling averages of ozone concentrations during the month and quarter before the interview. $\boldsymbol{X}_{i t}^{\prime}$ is a matrix of time-varying individual level controls and $\boldsymbol{Y}_{c t}^{\prime}$ contains county and weather controls. $\gamma_{t}$ contains the matrix of time fixed effects, year fixed, and weekday fixed effects. $\lambda_{i}$ are individual fixed effects, and $\epsilon_{i t}$ is the error term, clustered at the household level.

Moreover, we analyze the impact of ozone exposure on the number of workdays lost because their child is sick using a fixed-effects Poisson model controlling for the same battery of covariates as in the main design. Finally, in the robustness section, we address the dependent variable's ordinal nature with the use of fixed effects probit models. Both the Poisson and the probit regressions control for individual and year fixed effects.

\section{Results}

\subsection{Full Sample}

We begin our analysis by considering if variation in exposure to ozone concentrations during the week before the interview affects the life or health satisfaction of individuals in the full sample. For each outcome, we run six different specifications, building up from a model containing only the level of ozone and fixed effects (Table 2, column 1) to a full multi-pollutant design controlling for the level of ozone, socio-demographic variables, macroeconomic controls, weather covariates, individual fixed effects, and time fixed effects (column 6). The latter is our preferred specification.

In the preferred multi-pollutant specification, the point estimate for ozone is negative and 
Table 2: Short-term effect of ozone on life satisfaction, full sample

\begin{tabular}{|c|c|c|c|c|c|c|}
\hline & \multicolumn{6}{|c|}{ Dependent variable: Life satisfaction } \\
\hline & $(1)$ & $(2)$ & (3) & (4) & $(5)$ & $(6)$ \\
\hline Ozone & $-0.002^{+}$ & $-0.002^{+}$ & $-0.002^{+}$ & -0.001 & -0.001 & -0.001 \\
\hline Income & & & & & & $0.001^{* *}$ \\
\hline Age & & $-0.013^{*}$ & $-0.025^{* * *}$ & $-0.025^{* * *}$ & $-0.025^{* * *}$ & $-0.027^{* * *}$ \\
\hline Unemployment & & $-0.397^{* * *}$ & $-0.395^{* * *}$ & $-0.398^{* * *}$ & $-0.399^{* * *}$ & $-0.398^{* * *}$ \\
\hline & & $(0.057)$ & $(0.057)$ & $(0.057)$ & $(0.057)$ & $(0.057)$ \\
\hline GDP & & & -0.000 & -0.000 & -0.000 & 0.000 \\
\hline Unemployment rate & & & $\begin{array}{l}(0.002) \\
-0.033^{* *}\end{array}$ & $\begin{array}{l}(0.002) \\
-0.033^{* *}\end{array}$ & $\begin{array}{l}(0.002) \\
-0.032^{* *}\end{array}$ & $\begin{array}{l}(0.002) \\
-0.032^{* *}\end{array}$ \\
\hline & & & $(0.012)$ & $(0.012)$ & $(0.012)$ & $(0.012)$ \\
\hline PM 25 & & & & & & $\begin{array}{l}-0.003 \\
(0.002)\end{array}$ \\
\hline Carbon monoxide & & & & & & 0.062 \\
\hline Sulfur dioxide & & & & & & $\begin{array}{l}(0.106) \\
-0.008\end{array}$ \\
\hline Nitrous dioxide & & & & & & $\begin{array}{c}(0.009) \\
0.005 \\
(0.003)\end{array}$ \\
\hline \multicolumn{7}{|l|}{ Included controls } \\
\hline Sociodemographic controls & & $\checkmark$ & $\checkmark$ & $\checkmark$ & $\checkmark$ & $\checkmark$ \\
\hline Macro controls & & & $\checkmark$ & $\checkmark$ & $\checkmark$ & $\checkmark$ \\
\hline Weather controls & & & & $\checkmark$ & $\checkmark$ & $\checkmark$ \\
\hline \multicolumn{7}{|l|}{ Included fixed effects } \\
\hline Individual & $\checkmark$ & $\checkmark$ & $\checkmark$ & $\checkmark$ & $\checkmark$ & $\checkmark$ \\
\hline Year & $\checkmark$ & $\checkmark$ & $\checkmark$ & $\checkmark$ & $\checkmark$ & $\checkmark$ \\
\hline Month & & & & $\checkmark$ & $\checkmark$ & $\checkmark$ \\
\hline Day-of-the-week & & & & & $\checkmark$ & $\checkmark$ \\
\hline No. Observations & 46,677 & 46,677 & 46,677 & 46,677 & 46,677 & 46,677 \\
\hline
\end{tabular}

Table notes: ${ }^{* * *} p<0.001,{ }^{* *} p<0.01,{ }^{*} p<0.05,{ }^{+} p<0.1$. OLS regressions of life satisfaction on ozone exposure during the week prior to the SOEP interview. All regressions contain individual and year fixed effects. Specification (1) contains ozone, individual fixed effects and year fixed effects. The other specifications add further controls while always keeping the covariates from the previous specification: (2) adds the sociodemographic covariates age, income, and unemployment status; (3) adds county-level macro covariates population density, gross domestic product, and unemployment rate; (4) adds sunshine duration, temperature, temperature squared, precipitation, and month fixed effects; (5) adds day-of-the-week fixed effects; (6) adds additional pollutants carbon monoxide, nitrous dioxide, sulfur dioxide, fine particulate matter. Robust standard errors clustered at the household level in parentheses.

insignificant. Additionally, we also find no significant effects for the other pollutants in the full sample. The results for other covariates are as expected and in concordance with Frijters et al. (2004): Age, being unemployed, and the unemployment rate of the county in which the individual resides are all negatively related to life satisfaction. Income, on the other hand, is positively associated with life satisfaction. As we are not only interested in the effect of ozone on subjective evaluations of people's lives but also their subjective health, we run the same 
exercise with health satisfaction as the dependent variable. In line with Levinson (2012), we find that ozone has no short-term effect on individuals' health satisfaction?

Next, we analyze the effect of different time aggregations of exposure to ozone on life satisfaction. Doing so is of interest as the epidemiological literature suggests that the adverse effects of ozone accumulate over time. We run additional estimations for average ozone concentrations during the month and quarter before the interview. Additionally, we also compute the corresponding rolling means of the other pollutants included in the multi-pollutant specification. Table 3 shows the coefficients on ozone for the weekly, monthly, and quarterly time aggregations and across all models $\sqrt[10]{10}$ Again, there is little evidence of a significant link between ozone and life satisfaction in the full sample. The results for health satisfaction are never significant for any time aggregation of ozone exposure.

Table 3: Effect of ozone on life satisfaction, full sample and different time aggregations of pollution

\begin{tabular}{|c|c|c|c|c|c|c|}
\hline & \multicolumn{6}{|c|}{ Dependent variable: Life satisfaction } \\
\hline & $(1)$ & $(2)$ & (3) & $(4)$ & $(5)$ & $(6)$ \\
\hline Weekly Ozone & -0.003 & -0.003 & -0.003 & -0.003 & -0.003 & $-0.006^{+}$ \\
\hline \multirow{2}{*}{ Monthly Ozone } & $\begin{array}{l}(0.002) \\
-0.000\end{array}$ & $\begin{array}{c}(0.002) \\
0.000\end{array}$ & $\begin{array}{c}(0.002) \\
0.000\end{array}$ & $\begin{array}{c}(0.003) \\
0.001\end{array}$ & $\begin{array}{c}(0.003) \\
0.001\end{array}$ & $\begin{array}{l}(0.003) \\
-0.001\end{array}$ \\
\hline & $(0.003)$ & $(0.003)$ & $(0.003)$ & $(0.003)$ & $(0.003)$ & $(0.004)$ \\
\hline \multirow[t]{2}{*}{ Quarterly Ozone } & -0.000 & 0.000 & 0.000 & 0.001 & 0.001 & 0.001 \\
\hline & $(0.003)$ & $(0.003)$ & $(0.003)$ & $(0.003)$ & $(0.003)$ & $(0.006)$ \\
\hline No. Observations & 46,677 & 46,677 & 46,677 & 46,677 & 46,677 & 46,677 \\
\hline
\end{tabular}

Table notes: ${ }^{* * *} p<0.001,{ }^{* *} p<0.01,{ }^{*} p<0.05,{ }^{+} p<0.1$. OLS regressions of life satisfaction on ozone exposure. All regressions contain individual and year fixed effects. Specification (1) contains ozone, individual fixed effects and year fixed effects. The other specifications add further controls while always keeping the covariates from the previous specification: (2) adds the sociodemographic covariates age, income, and unemployment status; (3) adds county-level macro covariates population density, gross domestic product, and unemployment rate; (4) adds sunshine duration, temperature, temperature squared, precipitation, and month fixed effects; (5) adds day-of-the-week fixed effects; (6) adds additional pollutants carbon monoxide, nitrous dioxide, sulfur dioxide, coarse particulate matter. Estimations are performed using three different temporal aggregations of pollution exposure: weekly, monthly, and quarterly. Robust standard errors clustered at the household level in parentheses.

These initial results for the full sample show that levels of ozone are not significantly related to how individuals assess their life or health satisfaction. This finding is in concordance with the results of Levinson (2012), who discovers a surprising lack of significance of ozone on the life satisfaction of U.S. households, but does not pursue this line of inquiry further. Next,

\footnotetext{
${ }^{9}$ For brevity, we do not show the results for health satisfaction. They are available upon request.

${ }^{10} \mathrm{We}$ also run our regressions using daily pollution data. Ozone is never found to be significant. We believe this result to be reasonable, due to the short measurement period. The results are available upon request.
} 
we revisit our hypothesis by studying if ozone has a significant impact on individuals sharing their households with children. All further analyses focus on our preferred specification.

\subsection{Households with and without children}

Recall that our central hypothesis is that ozone affects adults' well-being through the impact of ozone on their children. If it holds, we expect the point estimate of ozone exposure on the life satisfaction of adults sharing a household with children to be significant and negative in sign, while the same point estimate for persons without children should remain insignificant. Table 4 contains the coefficients of our preferred specification across three different time aggregations of ozone levels, for the subsamples of persons with and without children, and for both life and health satisfaction.

Table 4: Effect of ozone on life and health satisfaction, by child status

\begin{tabular}{|c|c|c|c|c|}
\hline & \multicolumn{2}{|c|}{ Life satisfaction } & \multicolumn{2}{|c|}{ Health satisfaction } \\
\hline & No children & Children & No children & Children \\
\hline Weekly ozone & $\begin{array}{l}-0.000 \\
(0.001)\end{array}$ & $\begin{array}{c}-0.005^{*} \\
(0.002)\end{array}$ & $\begin{array}{c}0.001 \\
(0.001)\end{array}$ & $\begin{array}{c}0.001 \\
(0.002)\end{array}$ \\
\hline Monthly ozone & $\begin{array}{c}0.001 \\
(0.002)\end{array}$ & $\begin{array}{c}-0.007^{*} \\
(0.003)\end{array}$ & $\begin{array}{c}0.001 \\
(0.002)\end{array}$ & $\begin{array}{c}0.001 \\
(0.003)\end{array}$ \\
\hline Quarterly ozone & $\begin{array}{c}0.002 \\
(0.002) \\
\end{array}$ & $\begin{array}{c}-0.009^{* *} \\
(0.003) \\
\end{array}$ & $\begin{array}{c}0.003 \\
(0.003) \\
\end{array}$ & $\begin{array}{c}0.002 \\
(0.003) \\
\end{array}$ \\
\hline No. Observations & 30,591 & 16,086 & 30,591 & 16,086 \\
\hline
\end{tabular}

Table notes: ${ }^{* * *} p<0.001,{ }^{* *} p<0.01,{ }^{*} p<0.05,{ }^{+} p<0.1$. OLS regressions of life satisfaction and health satisfaction on ozone exposure in a multipollutant model controlling for individual fixed effects, year fixed effects, month fixed effects and day-of-the-week fixed effects; sociodemographic covariates age, income, and unemployment status; county-level macro covariates population density, gross domestic product, and unemployment rate; sunshine duration, temperature, temperature squared, precipitation; air pollutants carbon monoxide, nitrous dioxide, sulfur dioxide, fine particulate matter. Estimations are performed using three different temporal aggregations of pollution exposure: weekly, monthly, and quarterly. Robust standard errors clustered at the household level in parentheses.

We find a statistically significant effect of ozone on the life satisfaction of adults with children. In contrast, we find no significant results for persons without children. Results show that a marginal increase in ozone decreases life satisfaction between 0.005 and 0.009 points, depending on the level of temporal aggregation. When extending the time interval for measuring exposure before the interview, the coefficient grows in size, pointing to time accumulation of adverse outcomes. A one-standard-deviation increase in ozone exposure decreases life satisfaction between 0.061 and 0.11 points. This effect corresponds up to about $15.5-27.9 \%$ of the 
impact of becoming unemployed, as estimated in table 2, one of the strongest shocks on life satisfaction found in the literature (Kassenboehmer and Haisken-DeNew, 2009).

Concerning health satisfaction, we find no significance for both adults with and without children. This result implies that the effect of ozone on the well-being of adults works - at least partially - indirectly: Ozone exposure diminishes adults' well-being due to the negative impact of ozone on their children, a well-known high-risk group. In additional unreported results differentiating by the age of the youngest child, we find that these results are driven by children of primary school age. 11

\section{Mechanism}

\subsection{Effect of ozone on children's health}

We have shown that ozone affects parents' life satisfaction while remaining innocuous to childless persons. An intuitive explanation is that the health of children influences parents' wellbeing. To corroborate this claim, we now present evidence of the negative health impact of ozone on SOEP children. As shown in section 2, there is a large stream of epidemiological literature demonstrating the negative consequences of ozone exposure for kid's health. However, it may be that ozone levels in Germany are too low to deteriorate the health of the children in our sample.

Unfortunately, we do not have access to direct health outcomes for SOEP children. Consequently, we cannot directly test whether ozone exposure affects their health. However, the SOEP does contain one relevant variable providing at least suggestive evidence in this regard; the number of workdays respondents lost in the previous year because their child was sick. ${ }^{12}$ If workdays lost due to child sickness are significantly affected by ozone, this provides evidence that ozone affects the health of children in the sample.

Since we only know the number of missed workdays due to child sickness in the previous calendar year, we require an explanatory variable indicating exposure to high ozone concentrations in year $t-1$ to establish the link between ozone and children's health. Computing this variable is not straightforward, as we need to consider both the variance and mean of expo-

\footnotetext{
${ }^{11}$ These other results are available upon request.

${ }^{12}$ The variable stems from the following SOEP question: "Leaving aside sick leave and vacation: Was there any other point in the previous calendar year when you did not work for other, personal reasons?" If the person answers; "Yes, because of a sick child," the interviewer asks for the number of missed days.
} 
sure in the previous calendar year. For instance, a simple annual average does not distinguish between households exposed to moderate ozone levels throughout the year and families experiencing high ozone levels in the summertime and low levels in winter. But without considering the variance of exposure, the average of these two groups are similar even though the impact of ozone on households with more extreme ozone levels is likely to be stronger.

To overcome these limitations, we need to identify individuals who experienced high ozone levels during the last year regardless of the underlying variance of personal exposure. To do so, we concentrate on the group of adults on the high-end tail of the exposure distribution. In principle, belonging to this group ensures a consistent exposure to higher ozone levels, while reducing concerns regarding noise stemming from the variance, i.e., an individual in the top percentile of the distribution is more affected by ozone than the majority of the population regardless of experiencing single ozone peaks. We capture the effect of this high-exposure subgroup on missed workdays because a child is sick with a binary variable indicating whether parents' average annual exposure to ozone is above the $90 \%$ percentile.

We estimate the effect of belonging to the high ozone concentration group on workdays lost by using a fixed-effects Poisson model. A Poisson model is appropriate because it allows the incorporation of many zero values in the outcome variable; the SOEP reports $66 \%$ of zero missed workdays during the sample period. We present the results for three different specifications increasing in the number of control covariates: specification (1) includes sociodemographic controls, (2) adds macro variables, and (3) uses additional binary variables indicating whether an individual's annual exposure to $\mathrm{CO}, \mathrm{PM}_{25}$ or $\mathrm{SO}_{2}$ exceeds the $90 \%$ percentile threshold. Table 5 shows the results across all three designs.

Results show that the number of workdays missed because a child was sick increases by between 0.20 and 0.23 days when the parents' average yearly ozone exposure is higher than the $90 \%$ percentile threshold. While statistically significant, quantitatively, this is a rather moderate effect. Furthermore, it is worth noting that the point estimates of the sociodemographic covariates are reasonable, showing that our model is well specified. For instance, being married increases the number of days staying at home because of child sickness, indicating greater flexibility of married couples. Additionally, increasing income is also related positively to the number of missed workdays because a child was sick, suggesting that financial flexibility allows parents to miss more workdays.

These results suggest that ozone exposure, even at comparatively low levels as in our 
Table 5: Poisson regressions of missed work days due to child sickness

\begin{tabular}{|c|c|c|c|}
\hline & \multicolumn{3}{|c|}{ Dependent variable: Missed worked days } \\
\hline & $(1)$ & $(2)$ & (3) \\
\hline High ozone exposure & $\begin{array}{c}0.221^{* * *} \\
(0.058)\end{array}$ & $\begin{array}{c}0.1988^{* * *} \\
(0.058)\end{array}$ & $\begin{array}{c}0.2315^{* * *} \\
(0.066)\end{array}$ \\
\hline Income & $\begin{array}{c}11.070^{* * *} \\
(1.179)\end{array}$ & $\begin{array}{c}10.28^{* * *} \\
(1.187)\end{array}$ & $\begin{array}{c}10.16^{* * *} \\
(1.191)\end{array}$ \\
\hline Married & $\begin{array}{c}0.479^{* * *} \\
(0.068)\end{array}$ & $\begin{array}{c}0.534^{* * *} \\
(0.069)\end{array}$ & $\begin{array}{c}0.531^{* * *} \\
(0.069)\end{array}$ \\
\hline $\begin{array}{l}\text { Macro controls } \\
\text { Additional pollutants }\end{array}$ & & $\checkmark$ & $\begin{array}{l}\checkmark \\
\checkmark \\
\end{array}$ \\
\hline \multicolumn{4}{|l|}{ Included fixed effects } \\
\hline $\begin{array}{l}\text { Individual } \\
\text { Year }\end{array}$ & $\begin{array}{l}\checkmark \\
\checkmark\end{array}$ & $\begin{array}{l}\checkmark \\
\checkmark\end{array}$ & $\begin{array}{l}\checkmark \\
\checkmark\end{array}$ \\
\hline No. Observations & 3,277 & 3,277 & 3,277 \\
\hline
\end{tabular}

Table notes: ${ }^{* * *} p<0.001,{ }^{* *} p<0.01,{ }^{*} p<0.05,{ }^{+} p<0.1$. Poisson regressions of workdays missed because a child was sick on ozone exposure. All regressions contain individual and year fixed effects. Specification (1) contains the dummy indicating whether parent's average annual ozone exposure is above the $90 \%$ percentile threshold as well as the sociodemographic covariates age, income and marital status. The other specifications add further controls while always keeping the covariates from the previous specification: (2) adds county-level macro covariates population density, gross domestic product, and unemployment rate; (3) adds additional binary variables indicating whether the parent is above the $90 \%$ decile threshold of the average annual concentration of carbon monoxide, fine particulate matter or sulfur dioxide. Robust standard errors clustered at the household level in parentheses.

German sample, leads to child sickness. Note that we do not claim that the work absences channel fully captures the effect of ozone on adults' well-being. Instead, we interpret this as evidence that ozone exposure affects children's health, bolstering the case for this effect driving part of the well-being impact.

\subsection{The role of parents' income}

There is evidence that family environments exert substantial and long-lasting effects on child outcomes (Heckman and Mosso, 2014; Francesconi and Heckman, 2016). High-income families invest more heavily in their offspring, which includes financial (Carneiro and Ginja, 2016) and non-financial resources such as (quality) time spent with children and mentoring (Carneiro et al., 2013). If these findings translate to our context, we expect that higher-income individuals will be more sensitive to the effects of ozone on their children. To evaluate this hypothesis, we split the sample of adults with children into above-median and below-median earners and 
repeat the analysis shown in Table 4.

Table 6: Effect of ozone on life and health satisfaction of adults with children, by income group

\begin{tabular}{lcccc}
\hline & \multicolumn{2}{c}{ Life satisfaction } & \multicolumn{2}{c}{ Health satisfaction } \\
\hline & High income & Low income & High income & Low income \\
\hline \multirow{2}{*}{ Weekly ozone } & $-0.005^{+}$ & -0.000 & -0.003 & 0.001 \\
Monthly ozone & $(0.003)$ & $(0.003)$ & $(0.003)$ & $(0.003)$ \\
& $-0.007^{*}$ & -0.000 & -0.005 & 0.000 \\
Quarterly ozone & $(0.003)$ & $(0.003)$ & $(0.003)$ & $(0.004)$ \\
& $\left(0.010^{* *}\right.$ & 0.002 & -0.006 & 0.001 \\
No. Observations & 8,041 & $(0.004)$ & $(0.004)$ & $(0.004)$ \\
\hline \multirow{2}{*}{. } & 8,041 & 8,045 & 8,045 \\
\hline${ }^{* * *} p<0.001,{ }^{* *} p<0.01,{ }^{*} p<0.05,{ }^{+} p<0.1$ & &
\end{tabular}

Table notes: ${ }^{* * *} p<0.001,{ }^{* *} p<0.01,{ }^{*} p<0.05,{ }^{+} p<0.1$. OLS regressions of life satisfaction and health satisfaction on ozone exposure in a multipollutant model controlling for individual fixed effects, year fixed effects, month fixed effects, and day-of-the-week fixed effects; sociodemographic covariates age, income, and unemployment status; county-level macro covariates population density, gross domestic product, and unemployment rate; sunshine duration, temperature, temperature squared, precipitation; air pollutants carbon monoxide, nitrous dioxide, sulfur dioxide, fine particulate matter. The sample is split according to whether income of a person is above or below the median. Estimations are performed using three different temporal aggregations of pollution exposure: weekly, monthly, and quarterly. Robust standard errors clustered at the household level in parentheses.

The results show that high-income parents drive the well-being effect of ozone on individuals with children (Table 6). In contrast to below-median earners, the well-being of abovemedian adults significantly declines. This result is in line with the literature on parental investments in children, revealing that family dynamics conducive to different outcomes for children also appear to be at play for ozone.

\section{Robustness tests}

\subsection{Indirect well-being effects of other air pollutants}

This section analyzes the indirect well-being effects of other air contaminants. Particularly, we repeat the analysis performed in section 5.2 for sulfur dioxide $\left(\mathrm{SO}_{2}\right)$ and fine particulate matter $\left(\mathrm{PM}_{25}\right)$. Table 7 shows that monthly average $\mathrm{SO}_{2}$ decreases the life satisfaction of individuals with children while not affecting the well-being of people without. Although the results are less significant than for ozone, their point estimates are larger. Overall, for households with children, coefficients are borderline significant at the ten percent level, while for families without 
children, the point estimates are smaller and highly insignificant.

Table 7: Effect of sulfur dioxide on life and health satisfaction, by child status

\begin{tabular}{|c|c|c|c|c|}
\hline & \multicolumn{2}{|c|}{ Life satisfaction } & \multicolumn{2}{|c|}{ Health satisfaction } \\
\hline & No children & Children & No children & Children \\
\hline Weekly sulfur dioxide & $\begin{array}{l}-0.001 \\
(0.010)\end{array}$ & $\begin{array}{l}-0.029 \\
(0.018)\end{array}$ & $\begin{array}{c}0.007 \\
(0.012)\end{array}$ & $\begin{array}{c}0.003 \\
(0.023)\end{array}$ \\
\hline Monthly sulfur dioxide & 0.006 & $-0.034^{+}$ & -0.006 & -0.001 \\
\hline Quarterly sulfur dioxide & $\begin{array}{l}(0.011) \\
-0.010 \\
(0.013)\end{array}$ & $\begin{array}{c}(0.020) \\
-0.031 \\
(0.022)\end{array}$ & $\begin{array}{l}(0.013) \\
-0.004 \\
(0.015)\end{array}$ & $\begin{array}{c}(0.023) \\
-0.002 \\
(0.027)\end{array}$ \\
\hline No. Observations & 30,591 & 16,086 & 30,591 & 16,086 \\
\hline
\end{tabular}

Table notes: ${ }^{* * *} p<0.001,{ }^{* *} p<0.01,{ }^{*} p<0.05,{ }^{+} p<0.1$. OLS regressions of life satisfaction and health satisfaction on $\mathrm{PM}_{25}$ exposure in a multipollutant model controlling for individual fixed effects, year fixed effects, month fixed effects and day-of-the-week fixed effects; sociodemographic covariates age, income, and unemployment status; county-level macro covariates population density, gross domestic product, and unemployment rate; sunshine duration, temperature, temperature squared, precipitation; air pollutants carbon monoxide, nitrous dioxide and ozone. Estimations are performed using three different temporal aggregations of pollution exposure: weekly, monthly, and quarterly. Robust standard errors clustered at the household level in parentheses.

Table 8: Effect of fine particulate matter on life and health satisfaction, by child status

\begin{tabular}{|c|c|c|c|c|}
\hline & \multicolumn{2}{|c|}{ Life satisfaction } & \multicolumn{2}{|c|}{ Health satisfaction } \\
\hline & No children & Children & No children & Children \\
\hline Weekly fine PM & $\begin{array}{l}-0.002 \\
(0.002)\end{array}$ & $\begin{array}{c}-0.009^{*} \\
(0.004)\end{array}$ & $\begin{array}{l}-0.002 \\
(0.003)\end{array}$ & $\begin{array}{l}-0.000 \\
(0.005)\end{array}$ \\
\hline Monthly fine PM & 0.001 & -0.008 & $-0.007^{+}$ & -0.001 \\
\hline Quarterly fine PM & $\begin{array}{l}-0.002 \\
(0.004)\end{array}$ & $\begin{array}{l}-0.003 \\
(0.006)\end{array}$ & $\begin{array}{c}-0.010^{*} \\
(0.005)\end{array}$ & $\begin{array}{l}-0.003 \\
(0.007)\end{array}$ \\
\hline No. Observations & 30,591 & 16,086 & 30,591 & 16,086 \\
\hline
\end{tabular}

Table notes: ${ }^{* * *} p<0.001,{ }^{* *} p<0.01,{ }^{*} p<0.05,{ }^{+} p<0.1$. OLS regressions of life satisfaction and health satisfaction on $\mathrm{PM}_{25}$ exposure in a multipollutant model controlling for individual fixed effects, year fixed effects, month fixed effects and day-of-the-week fixed effects; sociodemographic covariates age, income, and unemployment status; county-level macro covariates population density, gross domestic product, and unemployment rate; sunshine duration, temperature, temperature squared, precipitation; air pollutants carbon monoxide, nitrous dioxide and ozone. Estimations are performed using three different temporal aggregations of pollution exposure: weekly, monthly, and quarterly. Robust standard errors clustered at the household level in parentheses.

Concerning $\mathrm{PM}_{25}$, table 8 shows that the life-satisfaction of individuals with children is negatively affected by $\mathrm{PM}_{25}$. The result is significant in the short term, while the monthly 
aggregation coefficient is borderline insignificant. The magnitude of point estimates is comparable to ozone. However, in contrast to ozone, the health satisfaction of childless individuals is significantly decreased by exposure to $\mathrm{PM}_{25}$, likely reflecting the more severe health impact of $\mathrm{PM}_{25}$ on older persons, which represent a significant proportion of childless individuals. When excluding individuals of retirement age (over 65 years of age), the health effect is no longer significant, while the impact on the life satisfaction of individuals with children remains $\sqrt{13}$ However, this decrease in health satisfaction does not translate into a reduction in life satisfaction for childless individuals. We find no significant effect of $\mathrm{PM}_{25}$ on people's health satisfaction, suggesting that the significant result on life satisfaction is not due to an impact on individuals' subjective health.

\subsection{Randomization of ozone exposure}

This section runs two sets of placebo regressions to test whether our main results are an artifact of a defect in our research design. We randomize pollutants across space by randomizing exposure over individuals from different parts of the country and across time by randomizing the exposure values of the same individual across the exposure values of all the years she was part of the panel. We then re-estimate our preferred specification. Table 9 contains the results of these additional estimations. Point estimates are always insignificant and very close to zero. Based on this exercise, we are confident that a flaw in our research design does not drive our main results.

\subsection{Cardinalization of well-being measures}

One caveat of this paper and others attempting to explain variation in subjective health and well-being is the cardinalization of ordinal data when running OLS type regressions (Levinson, 2012; Bond and Lang, 2018). The problem with cardinalizing ordinal scales is that we need to assume that the distance between values is the same: for example, the gap between zero and one is the same as between nine and ten. Changing the distance between them is a monotonic transformation of the ordinal scale. Such monotonic transformations may alter and even reverse regression results obtained by treating ordinal data as cardinal (Bond and Lang, 2018).

We run fixed-effects probit models to analyze if our results hold up when treating our

\footnotetext{
${ }^{13}$ These additional results are available upon request.
} 
Table 9: Spatial and temporal randomization of pollutants, by child status

\begin{tabular}{lcccc}
\hline & \multicolumn{2}{c}{ Life satisfaction } & \multicolumn{2}{c}{ Health satisfaction } \\
\hline & No children & Children & No children & Children \\
\hline Spatial randomization & & & & \\
Weekly ozone & -0.000 & -0.000 & 0.000 & 0.000 \\
Monthly ozone & $(0.001)$ & $(0.001)$ & $(0.001)$ & $(0.001)$ \\
& 0.000 & 0.000 & 0.001 & 0.001 \\
Quarterly ozone & $(0.001)$ & $(0.001)$ & $(0.001)$ & $(0.001)$ \\
& -0.000 & -0.000 & 0.002 & 0.002 \\
Temporal randomization & $(0.001)$ & $(0.001)$ & $(0.001)$ & $(0.001)$ \\
Weekly ozone & & & & \\
Monthly ozone & 0.000 & 0.000 & -0.001 & -0.001 \\
Quarterly ozone & $(0.001)$ & $(0.001)$ & $(0.001)$ & $(0.001)$ \\
& -0.000 & -0.000 & -0.001 & -0.001 \\
& $(0.001)$ & $(0.001)$ & $(0.001)$ & $(0.001)$ \\
No. Observations & -0.001 & -0.001 & 0.002 & 0.002 \\
& $(0.001)$ & $(0.001)$ & $(0.002)$ & $(0.002)$ \\
\hline
\end{tabular}

Table notes: ${ }^{* * *} p<0.001,{ }^{* *} p<0.01,{ }^{*} p<0.05,{ }^{+} p<0.1$. OLS regressions of life satisfaction and health satisfaction on ozone exposure in a multipollutant model controlling for individual fixed effects, year fixed effects, month fixed effects and day-of-the-week fixed effects; sociodemographic covariates age, income, and unemployment status; county-level macro covariates population density, gross domestic product, and unemployment rate; sunshine duration, temperature, temperature squared, precipitation; air pollutants carbon monoxide, nitrous dioxide, sulfur dioxide, fine particulate matter. Estimations are performed using three different temporal aggregations of pollution exposure: weekly, monthly, and quarterly. Robust standard errors clustered at the household level in parentheses.

subjective outcomes as ordinal. ${ }^{14}$ We transform the health and life satisfaction scales into binary variables using a number of different cut-off points $c_{j}$ for $j=(2, \ldots, 9)$. For example, consider the cut-off point 2: If an individual's life satisfaction is smaller than or equal to 2, we assign a value of zero; that is, the individual is deemed "unhappy." If life satisfaction is greater than 2, we assign a 1; that is, the individual is considered "happy." Therefore, low cut-offs place more people in the "happy" group, while the reverse is true for high cut-off points. Note that the location of the cut-off is arbitrary. Without information on the underlying distribution of happiness, it isn't possible to make precise assessments on the suitability of a cut-off. We thus consider our results to be robust if they hold for multiple cut-off points.

Table 10 contains the Probit estimations for the sample of adults with children in the preferred specification. Results show that point estimates for life satisfaction are always negative and significant for multiple cut-off points. Almost irrespective of the cut-off point, our results

\footnotetext{
${ }^{14}$ We use the unconditional bias-corrected probit algorithm developed by Stammann et al. (2016). The algorithm uses the unconditional probit framework that corrects for the incidental parameters problem (Neyman and Scott, 1948) with the jackknife procedure developed in Hahn and Newey (2004).
} 
are significant for the longer-term aggregations at monthly or quarterly frequencies. As in our baseline analysis, there are no significant results for health. Moreover, the corresponding table for the sample of childless people yields no significant results either for life satisfaction or health satisfaction, also confirming the results from the baseline regressions. ${ }^{15}$

Table 10: Probit estimations of effect of ozone on life and health satisfaction, adults with children

\begin{tabular}{lccccccccc}
\hline & $(1)$ & $(2)$ & $(3)$ & $(4)$ & $(5)$ & $(6)$ & $(7)$ & $(8)$ \\
\hline \multicolumn{7}{c}{ Dependent variable Life satisfaction } \\
\hline \multirow{2}{*}{ Weekly Ozone } & $-0.014^{+}$ & $-0.011^{*}$ & $-0.009^{*}$ & -0.005 & -0.005 & -0.002 & $-0.006^{*}$ & 0.001 \\
& $(0.009)$ & $(0.006)$ & $(0.005)$ & $(0.003)$ & $(0.003)$ & $(0.003)$ & $(0.003)$ & $(0.005)$ \\
Monthly Ozone & $-0.021^{*}$ & $-0.013^{*}$ & $-0.010^{+}$ & $-0.007^{+}$ & $-0.006^{+}$ & -0.003 & $-0.007^{*}$ & 0.000 \\
& $(0.010)$ & $(0.006)$ & $(0.005)$ & $(0.004)$ & $(0.003)$ & $(0.003)$ & $(0.003)$ & $(0.006)$ \\
Quarterly Ozone & $-0.026^{*}$ & $-0.017^{*}$ & $-0.012^{+}$ & $-0.009^{+}$ & $-0.007^{+}$ & $-0.006^{+}$ & $-0.008^{*}$ & -0.002 \\
& $(0.012)$ & $(0.008)$ & $(0.006)$ & $(0.005)$ & $(0.004)$ & $(0.003)$ & $(0.004)$ & $(0.007)$
\end{tabular}

Dependent variable: Health satisfaction

\begin{tabular}{|c|c|c|c|c|c|c|c|c|}
\hline Weekly Ozone & $\begin{array}{c}0.003 \\
(0.006)\end{array}$ & $\begin{array}{c}0.002 \\
(0.004)\end{array}$ & $\begin{array}{c}0.004 \\
(0.004)\end{array}$ & $\begin{array}{l}-0.001 \\
(0.003)\end{array}$ & $\begin{array}{l}-0.003 \\
(0.003)\end{array}$ & $\begin{array}{l}-0.000 \\
(0.002)\end{array}$ & $\begin{array}{c}-0.002 \\
(0.003)\end{array}$ & $\begin{array}{l}-0.000 \\
(0.004)\end{array}$ \\
\hline Monthly Ozone & 0.004 & 0.003 & 0.002 & -0.001 & -0.003 & 0.000 & -0.003 & -0.001 \\
\hline \multirow{3}{*}{ Quarterly Ozone } & $(0.007)$ & $(0.005)$ & $(0.004)$ & $(0.003)$ & $(0.003)$ & $(0.003)$ & $(0.003)$ & $(0.004)$ \\
\hline & 0.001 & 0.005 & 0.005 & -0.001 & -0.003 & 0.003 & -0.001 & -0.001 \\
\hline & $(0.009)$ & $(0.006)$ & $(0.005)$ & $(0.004)$ & $(0.004)$ & $(0.003)$ & $(0.004)$ & $(0.005)$ \\
\hline No. Observations & 1,908 & 3,899 & 5,935 & 9,993 & 12,947 & 15,749 & 10,245 & 3,565 \\
\hline
\end{tabular}

Table notes: ${ }^{* * *} p<0.001,{ }^{* *} p<0.01,{ }^{*} p<0.05,{ }^{+} p<0.1$. Fixed-effects probit regressions of life satisfaction and health satisfaction on ozone exposure in a multipollutant model controlling for individual fixed effects, year fixed effects, month fixed effects, and day-of-the-week fixed effects; sociodemographic covariates age, income, and unemployment status; county-level macro covariates population density, gross domestic product, and unemployment rate; sunshine duration, temperature, temperature squared, precipitation; air pollutants carbon monoxide, nitrous dioxide, sulfur dioxide, fine particulate matter. Estimations are performed using three different temporal aggregations of pollution exposure: weekly, monthly, and quarterly. Each columm relates to a specific cut-off point between 2 and 9 used to transform the original 11-point scale into a happiness status of 0 or 1 . The estimated specifications and cut-off points $c_{j} \in j=(2, \ldots, 9)$ are related as follows: $\left[(1)=c_{2}, \ldots,(8)=c_{9}\right]$. Robust standard errors clustered at the household level in parentheses.

\section{Summary and conclusion}

This paper hypothesizes that air pollution may - in addition to a direct health effect - decrease adults' well-being through its impact on their children. The study tests this hypothesis for the case of ground-level ozone by analyzing whether ozone exposure affects individuals with and without children in different ways. We use a representative panel of German individuals, the German Socio-Economic Panel Study (SOEP), to study the effect of exposure to ground-level

\footnotetext{
${ }^{15}$ To limit the number of tables we do not report these results here. They are available upon request.
} 
ozone on two measures of subjective well-being, health and life satisfaction. Moreover, we provide direct evidence on the children's health channel to adults' life satisfaction by analyzing whether ozone exposure forces adults to stay home caring for their sick child. Our analysis also evaluates heterogeneity in the well-being effect introduced by parents' income, in line with the literature on parental investments in their children.

We exploit information on the precise date of the SOEP interview to identify the effect of ozone on individuals from short-term variation in ozone levels. To do so, we match pollution levels from measuring stations across Germany with geo-coded SOEP data between 2005 and 2015 and compute the individual level of exposure through inverse distance weighting techniques. The study estimates the effects of ozone on the health and life satisfaction of adults with and without children using multi-pollutant fixed effects regressions. In the preferred specification, we control for time and individual fixed effects and include a battery of individual, county, and weather covariates to account for observable and unobservable heterogeneity.

We find statistically and economically significant adverse effects of ozone on the life satisfaction of adults sharing a household with children while finding no impacts on childrenless households. In contrast to life satisfaction, our analysis finds no evidence of a direct effect of ozone on adults' health satisfaction. Examining the children's health mechanism to losses in adults' life satisfaction, we find that higher ozone exposure leads to a significant increase in workdays lost because a child was sick. In line with the literature on parental investments, the well-being effect is concentrated among above-median earners. Our results suggest that ozone concentrations in Germany are not high enough to affect the subjective health of adults, but that they do have negative consequences for the health of children, which in turn diminishes the well-being of adults sharing the household with them.

Based on our analysis, we recommend considering the indirect influence of ozone on persons with children for future research dealing with the cost-benefit analysis of ozone-related environmental policies. One limitation of our study is the lack of access to direct measures of health data for children. Further research should attempt to shed additional light on the children's health mechanism to losses in life satisfaction of adults identified in this paper by analyzing the impact of ozone on children using objective data. 


\section{References}

Ambrey C. L., Fleming C. M., and Chan A. Y.-C. (2014) Estimating the cost of air pollution in South East Queensland: An application of the life satisfaction non-market valuation approach. Ecological Economics, 97: 172-181.

Amster E. D., Haim M., Dubnov J., and Broday D. M. (2014) Contribution of nitrogen oxide and sulfur dioxide exposure from power plant emissions on respiratory symptom and disease prevalence. Environmental pollution, 186: 20-28.

Aragon F., Miranda J. J., Oliva P. et al. (2016) Particulate matter and labor supply: evidence from Peru. Simon Fraser University Economics Working Paper. Google Scholar.

Barwick P. J., Li S., Rao D., and Zahur N. B. (2018) The Morbidity Cost of Air Pollution: Evidence from Consumer Spending in China. NBER Working Paper No. 24688.

Bates D. V. (1995) The effects of air pollution on children.. Environmental Health Perspectives, 103(suppl 6): 49-53.

Bond T. N. and Lang K. (2018) The Sad Truth About Happiness Scales: Empirical Results. Technical report, National Bureau of Economic Research.

Burnett R. T., Smith-Doiron M., Stieb D., Raizenne M. E., Brook J. R., Dales R. E., Leech J. A., Cakmak S., and Krewski D. (2001) Association between ozone and hospitalization for acute respiratory diseases in children less than 2 years of age. American Journal of Epidemiology, 153(5): 444-452.

Carneiro P. and Ginja R. (2016) Partial insurance and investments in children. The Economic Journal, 126(596): F66-F95.

Carneiro P., Meghir C., and Parey M. (2013) Maternal education, home environments, and the development of children and adolescents. Journal of the European Economic Association, 11(suppl_1): 123-160.

Chang T. Y., Graff Zivin J., Gross T., and Neidell M. (2019) The effect of pollution on worker productivity: evidence from call center workers in China. American Economic Journal: Applied Economics, 11(1): 151-72. 
Chay K. Y. and Greenstone M. (2003) Air quality, infant mortality, and the Clean Air Act of 1970.Technical report, National Bureau of Economic Research.

Chen S., Guo C., and Huang X. (2018) Air Pollution, Student Health, and School Absences: Evidence from China. Journal of Environmental Economics and Management, 92: 465-497.

Cunado J. and De Gracia F. P. (2013) Environment and happiness: New evidence for Spain. Social Indicators Research, 112(3): 549-567.

Currie J., Hanushek E. A., Kahn E. M., Neidell M., and Rivkin S. G. (2009) Does pollution increase school absences? The Review of Economics and Statistics, 91(4): 682-694.

De Mesnard L. (2013) Pollution models and inverse distance weighting: Some critical remarks. Computers \& Geosciences, 52: 459-469.

Devlin R. B., McDonnell W. F., Mann R., Becker S., House D. E., Schreinemachers D., and Koren H. S. (1991) Exposure of humans to ambient levels of ozone for 6.6 hours causes cellular and biochemical changes in the lung. Am J Respir Cell Mol Biol, 4(1): 72-81.

EPA (2016) Ozone and Your Patients' Health - Online Course for Medical Professionals. Environment Protection Agency.

Ferreira S., Akay A., Brereton F., Cuñado J., Martinsson P., Moro M., and Ningal T. F. (2013) Life satisfaction and air quality in Europe. Ecological Economics, 88: 1-10.

Ferreira S. and Moro M. (2010) On the use of subjective well-being data for environmental valuation. Environmental and Resource Economics, 46(3): 249-273.

Francesconi M. and Heckman J. J. (2016) Child Development and Parental Investment: Introduction. The Economic Journal, 126(596): F1-F27.

Friedman M. S., Powell K. E., Hutwagner L., Graham L. M., and Teague W. G. (2001) Impact of changes in transportation and commuting behaviors during the 1996 Summer Olympic Games in Atlanta on air quality and childhood asthma. Jama, 285(7): 897-905.

Frijters P., Haisken-DeNew J. P., and Shields M. A. (2004) Investigating the patterns and determinants of life satisfaction in Germany following reunification. Journal of Human Resources, 39(3): 649-674. 
Galizia A. and Kinney P. L. (1999) Long-term residence in areas of high ozone: associations with respiratory health in a nationwide sample of nonsmoking young adults [dsee comments]. Environmental Health Perspectives, 107(8): 675.

Gryparis A., Forsberg B., Katsouyanni K., Analitis A., Touloumi G., Schwartz J., Samoli E., Medina S., Anderson H. R., Niciu E. M. et al. (2004) Acute effects of ozone on mortality from the air pollution and health: a European approach project. American journal of respiratory and critical care medicine, 170(10): 1080-1087.

Hahn J. and Newey W. (2004) Jackknife and analytical bias reduction for nonlinear panel models. Econometrica, 72(4): 1295-1319.

Hanna R. and Oliva P. (2015) The effect of pollution on labor supply: Evidence from a natural experiment in Mexico City. Journal of Public Economics, 122: 68-79.

Heckman J. J. and Mosso S. (2014) The economics of human development and social mobility. Anпu. Rev. Econ., 6(1): 689-733.

Iskandar A., Andersen Z. J., Bønnelykke K., Ellermann T., Andersen K. K., and Bisgaard H. (2012) Coarse and fine particles but not ultrafine particles in urban air trigger hospital admission for asthma in children. Thorax, 67(3): 252-257.

Jayachandran S. (2009) Air quality and early-life mortality evidence from Indonesiaâs wildfires. Journal of Human Resources, 44(4): 916-954.

Kampa M. and Castanas E. (2008) Human health effects of air pollution. Environmental pollution, 151(2): 362-367.

Kassenboehmer S. C. and Haisken-DeNew J. P. (2009) Youâre Fired! the Causal Negative Effect of Entry Unemployment on Life Satisfaction. The Economic Journal, 119(536): 448462.

Kim K. J., Shin J., and Choi J. (2018) Cancer risk from exposure to particulate matter and ozone according to obesity and health-related behaviors: A nationwide population-based cross-sectional study. Cancer Epidemiology, Biomarkers \& Prevention.

Knittel C. R., Miller D. L., and Sanders N. J. (2016) Caution, Drivers! Children Present: Traffic, Pollution, and Infant Health. Review of Economics and Statistics, 98(2): 350-366. 
Koken P. J., Piver W. T., Ye F., Elixhauser A., Olsen L. M., and Portier C. J. (2003) Temperature, air pollution, and hospitalization for cardiovascular diseases among elderly people in Denver. Environmental Health Perspectives, 111(10): 1312.

Lee J.-T., Kim H., Song H., Hong Y.-C., Cho Y.-S., Shin S.-Y., Hyun Y.-J., and Kim Y.-S. (2002) Air pollution and asthma among children in Seoul, Korea. Epidemiology, 13(4): $481-484$.

Levinson A. (2012) Valuing public goods using happiness data: The case of air quality. Journal of Public Economics, 96(9-10): 869-880.

Lleras-Muney A. (2010) The needs of the army using compulsory relocation in the military to estimate the effect of air pollutants on childrenâs health. Journal of Human Resources, 45(3): 549-590.

Luechinger S. (2009) Valuing air quality using the life satisfaction approach. The Economic Journal, 119(536): 482-515.

Moretti E. and Neidell M. (2011) Pollution, health, and avoidance behavior evidence from the ports of Los Angeles. Journal of Human Resources, 46(1): 154-175.

Neyman J. and Scott E. L. (1948) Consistent estimates based on partially consistent observations. Econometrica: Journal of the Econometric Society: 1-32.

Ostro B., Lipsett M., Mann J., Braxton-Owens H., and White M. (2001) Air pollution and exacerbation of asthma in African-American children in Los Angeles. Epidemiology: 200208.

Rehdanz K. and Maddison D. (2008) Local environmental quality and life-satisfaction in Germany. Ecological Economics, 64(4): 787-797.

Richter D., Metzing M., Weinhardt M., and Schupp J. (2013) SOEP Scales Manual. SOEP Survey Papers: Series C - Data Documentations.

Rocks N., Vanwinge C., Gilles C., Gerard C., Blacher S., Noel A., and Cataldo D. (2017) A Role for Ozone Pollution in Lung Cancer Progression. American Journal of Respiratory and Critical Care Medicine. 
Rosenzweig C., Civerolo K., Ku J., and Kinney P. (2004) Assessing ozone-related health impacts under a changing climate. Environ Health Perspect, 112(15).

Schwela D. (2000) Air Pollution and Health in Urban Areas. Reviews on Environmental Health, 15(1-2): $13-42$.

Selin N. E., Wu S., Nam K.-M., Reilly J. M., Paltsev S., Prinn R. G., and Webster M. D. (2009) Global health and economic impacts of future ozone pollution. Environmental Research Letters, 4(4): 044014.

Shumaker B. and Sinnott R. (1984) Astronomical computing: 1. Computing under the open sky. 2. Virtues of the haversine.. Sky and Telescope, 68: 158-159.

Stammann A., Heiss F., and McFadden D. (2016) Estimating fixed effects logit models with large panel data.

Thurston G. D., Lippmann M., Scott M. B., and Fine J. M. (1997) Summertime haze air pollution and children with asthma.. American journal of respiratory and critical care medicine, 155(2): 654-660.

Tolbert P. E., Mulholland J. A., Macintosh D. L., Xu F., Daniels D., Devine O. J., Carlin B. P., Klein M., Butler A. J., Nordenberg D. F. et al. (2000) Air quality and pediatric emergency room visits for asthma and Atlanta, Georgia. American Journal of Epidemiology, 151(8): 798-810.

Wolff H. (2014) Keep Your Clunker in the Suburb: Low-emission Zones and Adoption of Green Vehicles. The Economic Journal, 124(578): F481-F512.

Zhang X., Zhang X., and Chen X. (2017) Happiness in the air: How does a dirty sky affect mental health and subjective well-being? Journal of Environmental Economics and Management, 85: 81-94.

Zivin J. G. and Neidell M. (2012) The impact of pollution on worker productivity. The American Economic Review, 102(7): 3652-3673. 